\title{
Comparison between endoscopic treatment and surgery for elderly population with early gastric cancer
}

\section{Yafen Tang}

Zhejiang University

Liang Luo

Zhejiang University

Xingkang He

Zhejiang University School of Medicine Sir Run Run Shaw Hospital

Haotian Chen ( $\sim$ 3414288@zju.edu.cn )

Research article

Keywords: Early gastric cancer, Endoscopic treatment, Surgery

Posted Date: July 2nd, 2020

DOI: https://doi.org/10.21203/rs.3.rs-38695/v1

License: (c) (1) This work is licensed under a Creative Commons Attribution 4.0 International License.

Read Full License 


\section{Abstract \\ Objective}

Despite of the declining incidence of gastric cancer, the number of elder patients with gastric cancer is increasing because of aging society. The appropriate treatment strategies for elderly patients have not yet been well defined. The aim of this study is sought to evaluate short- and long-term outcomes after different therapies for early gastric cancers in elderly populations.

\section{Methods}

We identified elderly patients aged $\geq 60$ years with early gastric cancer ( $T 1$ stage) from the Surveillance, Epidemiology and End Results (SEER) database during1998 to 2010. We compared clinic features between different treatment groups and evaluated 1-year, 3-year and 5-year cancer-specific survival outcomes.

\section{Results}

Totally 5639 elderly patients with early gastric cancer were identified from the SEER database (19982010). Among them, 2997 patients underwent surgical resection and 328 patients received endoscopic treatment (ET). In a Cox regression model, either surgery or endoscopic resection were associated with improved survival. The short- and long term survival for patients who underwent surgical or endoscopic resection were similar (one-year survival rate (SR) for surgery vs. ET, $89.3 \%$ vs. $89.9 \%, P>0.05$; five-year $\mathrm{SR}, 77.1 \%$ vs. $78.3 \%, P>0.05)$.

\section{Conclusions}

In elderly patients with early gastric cancer, short- and long term survival outcomes were similar between ET and the surgical groups, which indicated that endoscopic therapy is an appropriate and alternative approach for early gastric cancers in older western populations.

\section{Background}

Gastric cancer (GC) continues to be the fifth most common cancers and one of the leading causes of cancer-related deaths in the world ${ }^{1,2}$. It is well acknowledged that early detection and treatment have reduced mortality of gastric cancer recently ${ }^{3}$. Due to improved endoscopic equipment and technique, the ratio of early gastric cancer (EGC) to total gastric cancer is increasing, especially in the Asia ${ }^{4}$. According to the World Health Statistics, there were dramatically growing number of older population worldwide as a result of aging society advancement ${ }^{5,6}$. Therefore, the number of elderly patients diagnosed with early 
gastric cancer is increasing ${ }^{7,8}$. Despite gastrectomy is still considered as the first line treatment for EGC, the 5-year survival rate after surgery in elderly patients is worse compared with non-elderly population ${ }^{9}$. Recently, less-invasive techniques with resection, including endoscopic mucosal resection (EMR) and endoscopic submucosal dissection (ESD) have come to been widely accepted as a preferred therapeutic approach for EGC without lymph node metastasis, especially in the Asia ${ }^{10-12}$. The advantage of endoscopic treatment (ET) was minimally invasive in relation to the surgical treatment. Considering elderly patients with comorbid disease or poor general function ${ }^{13}$, ET might be better tolerated in elderly patients because of less-invasive nature of this modality. In the past decade, the number of elderly EGC patients undergoing ET was strikingly increasing. Although previous studies had assessed the outcomes of EGC after ESD or EMR in general patients from Asia, reliable evidence about appropriate therapeutic choices for elderly patients seemed still lacking, especially for the western population. Because of high incidence of gastric cancer in the Asia, the majority of previous data was based on the Asian population. Therefore, we aimed to performed a retrospective cohort study using the Surveillance, Epidemiology and End Results (SEER) cancer registry data to investigated the short and long term survival outcomes of ET or surgery in elderly patients with early gastric cancer.

\section{Methods}

\section{Cohort population}

Patient data were obtained from the Surveillance, Epidemiology, and End Results (SEER)-a populationbased database, which covers approximately $28 \%$ of cancer cases in the United States. Patients were identified as following criteria: histologically confirmed, gastric adenocarcinoma (ICD-0-3M-8140/3 through M-8145/3, M-8210/3, M-8211/3, M-8255/3, M-8260/3 through M-8263/3, M-8310/3, M-8323/3, M-8480/3,M-8481/3, M-8490/3) diagnosed between 1994 and 2011, $60 \leq$ age $\leq 90$ at diagnosis, one primary cancer. Tumour stage was coded according to the American Joint Committee on Cancer (AJCC) TNM staging system, 7th edition. International Classification of Diseases for Oncology codes were used to identify patients with adenocarcinoma. Cases with tumour depth classified in lamina propria, muscularis mucosae, or submucosa (T1a and T1b) were included based on SEER variables for tumour extension. As detailed in Fig. 1, patients with stage IV disease or multiple primary cancers, or patients who received neoadjuvant radiation therapy were excluded. Detailed modalities about endoscopic treatment (i.e. ESD or EMR) were not evaluated because the database was unable to provide such detailed information. Endoscopic treatment and surgery were identified from site-specific surgery of primary site codes $\mathrm{C} 10-14,20-27$ and C30-33, C41-42, C50-52, C60-63, C80, C90, respectively. The detailed selection diagram of the population was presented in Fig. 1. Our study was exempt from the review board of the Sir Run Run Shaw Hospital, Zhejiang University School of Medicine due to the publicity of data.

\section{Statistical Analysis}


We compared the clinical characterises among treatment groups by Chi-square test. We adopted cancerspecific survival as endpoint. Kaplan-Meier curves were generated to compare survival between treatment groups and the log-rank test was used to test the null hypothesis. The univariable and multivariable Cox proportional hazards regression analyses were used to calculate corresponding hazard ratios (HRs) and 95\% confidence intervals (Cls) for treatment approaches and their association with survival time. Twosided $P$ values at the $P<0.05$ level was considered to be statistically significant. All analyses were performed with SPSS version 20.0 (SPSS, Chicago, Illinois, USA).

\section{Results}

Baseline clinicopathologic characteristics

From the SEER database, we identified 5639 elderly patients $(60 \leq$ age $\leq 90)$ with early gastric cancer (T1) from 1998 to 2010 and finally included them in the study. Figure 1. displays the detailed stepwise cohort identification. Among those population, 2997 (53.1\%) patients primarily underwent surgical resection and $328(5.8 \%)$ patients underwent endoscopic treatment. Additional, the remaining 2314 (41.0\%) patients who did not receive either ET or surgery. The mean follow-up duration was 3.5 years for patients. Baseline clinical characteristics for different treatment groups were showed in Table 1. Among patients received ET or surgery, there were no significant differences with respect to age, gender, tumour location. Patients undergoing ET were more likely to be married, diagnosis at recent year, well differentiated histology and T1a tumours, whereas patients who receiving surgery tended to have T1b tumour. 
Table 1

Baseline demographic characteristics for patients with early gastric cancer

\begin{tabular}{|c|c|c|c|c|}
\hline \multirow[t]{2}{*}{ Characteristics } & \multicolumn{3}{|l|}{ Treatment Approach } & \multirow[t]{2}{*}{$P$ value } \\
\hline & $\begin{array}{l}\text { No surgery or ET* } \\
(\mathrm{N}=2314)\end{array}$ & $\begin{array}{l}E T \\
(N=328)\end{array}$ & $\begin{array}{l}\text { Surgery } \\
(N=2997)\end{array}$ & \\
\hline Age(year) & & & & 0.991 \\
\hline $60-69$ & $623(26.9 \%)$ & $87(26.5 \%)$ & $812(27.1 \%)$ & \\
\hline $70-79$ & $864(37.3 \%)$ & $126(38.4 \%)$ & 1131(37.7\%) & \\
\hline $80-90$ & 827 (35.7\%) & 115(35.1\%) & 1054(35.2\%) & \\
\hline Gender & & & & 0.161 \\
\hline Male & 1342(58.0\%) & $207(63.1 \%)$ & 1786(59.6\%) & \\
\hline Female & $972(42.0 \%)$ & $121(36.9 \%)$ & 1211(40.4\%) & \\
\hline Race & & & & 0.043 \\
\hline White & 1566(67.7\%) & $210(64.0 \%)$ & 2040(68.1\%) & \\
\hline Black & $273(11.8 \%)$ & $51(15.5 \%)$ & $373(12.4 \%)$ & \\
\hline Other & $468(20.2 \%)$ & $67(20.4 \%)$ & $570(19.0 \%)$ & \\
\hline Unknown & $7(0.3 \%)$ & 0 & $14(0.5 \%)$ & \\
\hline Insurance & & & & 0.003 \\
\hline Insured & 712(30.8\%) & 102(31.1\%) & 1065(35.5\%) & \\
\hline Uninsured & $10(0.4 \%)$ & $1(0.3 \%)$ & $19(0.6 \%)$ & \\
\hline Unknown & 1592(68.8\%) & $225(68.6 \%)$ & 1913(63.8\%) & \\
\hline Marital status & & & & 0.03 \\
\hline Married & $1264(54.6 \%)$ & 182(55.5\%) & 1591(53.1\%) & \\
\hline Unmarried & $961(41.5 \%)$ & $122(37.2 \%)$ & $1271(42.4 \%)$ & \\
\hline Unknown & $89(3.8 \%)$ & $24(7.3 \%)$ & $135(4.5 \%)$ & \\
\hline Year at diagnosis & & & & 0.025 \\
\hline 1998-2001 & $569(24.6 \%)$ & $57(17.4 \%)$ & 725(24.2\%) & \\
\hline 2002-2005 & 759(32.8\%) & 105(32.0\%) & $995(33.2 \%)$ & \\
\hline 2006-2010 & $986(42.6 \%)$ & $166(50.6 \%)$ & 1277(42.6\%) & \\
\hline
\end{tabular}




\begin{tabular}{|c|c|c|c|c|}
\hline \multirow[t]{3}{*}{ Characteristics } & \multicolumn{3}{|c|}{ Treatment Approach } & \multirow[t]{3}{*}{$P$ value } \\
\hline & No surgery or ET* & ET & Surgery & \\
\hline & $(N=2314)$ & $(\mathrm{N}=328)$ & $(N=2997)$ & \\
\hline Grade & & & & $<0.001$ \\
\hline Well differentiated & $120(5.2 \%)$ & $54(16.5 \%)$ & $408(13.6 \%)$ & \\
\hline Moderately differentiated & $665(28.7 \%)$ & 97() $29.6 \%$ & $1084(36.2 \%)$ & \\
\hline Poorly differentiated & $1011(43.7 \%)$ & $59(18.0 \%)$ & $1206(40.2 \%)$ & \\
\hline Undifferentiated & $31(1.3 \%)$ & $2(0.6 \%)$ & $35(1.2 \%)$ & \\
\hline Unknown & $487(21.0 \%)$ & $116(35.4 \%)$ & $264(8.8 \%)$ & \\
\hline Primary location & & & & 0.074 \\
\hline Cardia & $667(28.8 \%)$ & $103(31.4 \%)$ & $882(29.4 \%)$ & \\
\hline Body & $653(28.2 \%)$ & $84(25.6 \%)$ & $791(26.4 \%)$ & \\
\hline Lower & $652(28.2 \%)$ & $96(29.3 \%)$ & $840(28.0 \%)$ & \\
\hline Overlapping lesion of stomach & $114(4.9 \%)$ & $6(1.8 \%)$ & $128(4.3 \%)$ & \\
\hline Stomach NOS & $228(9.9 \%)$ & $39(11.9 \%)$ & $356(11.9 \%)$ & \\
\hline Tumour extension & & & & $<0.001$ \\
\hline T1a & $568(24.5 \%)$ & $185(56.4 \%)$ & $999(33.3 \%)$ & \\
\hline T1b & $124(5.4 \%)$ & $56(17.1 \%)$ & $1643(54.8 \%)$ & \\
\hline T1NOS & 1622(70.1\%) & $87(26.5 \%)$ & $355(11.8 \%)$ & \\
\hline
\end{tabular}


Table 2

Univariable and multivariable Cox model of cancer-specific mortality

\begin{tabular}{|lllll|}
\hline Characteristics & Univariable & \multicolumn{3}{l|}{ Multivariable } \\
\hline Year at diagnosis & HR $(95 \% \mathrm{Cl})$ & P value & HR $(95 \% \mathrm{Cl})$ & P value \\
\hline 1998-2001 & Reference & & Reference & \\
\hline $2002-2005$ & $0.93(0.84,1.03)$ & 0.162 & $1.01(0.91,1.11)$ & 0.927 \\
\hline $2006-2010$ & $0.78(0.71,0.86)$ & $<0.001$ & $0.86(0.78,0.95)$ & 0.003 \\
\hline Grade & & & & \\
\hline Well differentiated & Reference & & Reference & \\
\hline Moderately differentiated & $1.76(1.18,2.09)$ & $<0.001$ & $1.36(1.14,1.62)$ & 0.001 \\
\hline Poorly differentiated & $2.40(2.03,2.83)$ & $<0.001$ & $1.75(1.48,2.07)$ & $<0.001$ \\
\hline Undifferentiated & $1.91(1.30,2.83)$ & 0.001 & $1.23(0.83,1.82)$ & 0.304 \\
\hline Unknown & $2.16(1.79,2.60)$ & $<0.001$ & $1.20(0.99,1.44)$ & 0.063 \\
\hline Treatment & & & & \\
\hline Surgery & Reference & & Reference & \\
\hline ET & $1.17(0.93,1.47)$ & 0.179 & $1.22(0.96,1.53)$ & 0.098 \\
\hline No surgery or ET & $7.30(6.63,7.96)$ & $<0.001$ & $6.15(5.57,6.80)$ & $<0.001$ \\
\hline Tumour extension & & & & \\
\hline T1NOS & Reference & & Reference & \\
\hline T1a & $0.29(0.26,0.32)$ & $<0.001$ & $0.63(0.57,0.70)$ & $<0.001$ \\
\hline T1b & $0.22(0.20,0.25)$ & $<0.001$ & $0.71(0.62,0.81)$ & $<0.001$ \\
\hline ET, Endoscopic Treatment; HR, Hazard Ratio; Cl, Confidence Interval. & \\
\hline
\end{tabular}


Table 3

Overall predictors of cancer-specific mortality in Cox proportional hazard models:

\begin{tabular}{|lll|}
\hline Variable & Hazard ratio $(95 \% \mathrm{Cl})$ * & $\mathbf{P}$ \\
\hline Age (year) & & \\
\hline $60-69$ & $1.01(0.64,1.61)$ & 0.955 \\
\hline $70-79$ & $0.69(0.49,0.97)$ & 0.035 \\
\hline $80-90$ & $0.83(0.54,1.29)$ & 0.416 \\
\hline Year at diagnosis & & \\
\hline $1998-2001$ & $0.61(0.40,0.93)$ & 0.023 \\
\hline 2002-2005 & $0.77(0.52,1.12)$ & 0.169 \\
\hline 2006-2010 & $0.96(0.64,1.45)$ & 0.855 \\
\hline Grade & & \\
\hline Well differentiated & $0.67(0.35,1.27)$ & 0.219 \\
\hline Moderately differentiated & $0.69(0.47,1.02)$ & 0.063 \\
\hline Poorly differentiated & $0.49(0.33,0.74)$ & 0.001 \\
\hline Undifferentiated & $0.08(0.01,1.19)$ & 0.067 \\
\hline Unknown & $1.04(0.58,1.84)$ & 0.905 \\
\hline Tumour extension & & 0.910 \\
\hline T1a & $0.73(0.49,1.07)$ & 0.102 \\
\hline T1b & $0.57(0.35,0.92)$ & 0.021 \\
\hline T1NOS & $1.02(0.69,1.52)$ & 0.96 \\
\hline * ET vs surgery, ET, reference. & \\
\hline & & \\
\hline
\end{tabular}

Short- and long-term outcomes

According to different treatment groups, elderly patients with $\mathrm{T} 1$ gastric cancer receiving neither surgery or ET were at higher risk of mortality compared with groups receiving either surgery or ET (Fig. 2). It demonstrates that either ET or surgery provide benefit for survival outcomes. However, as Kaplan-Meier survival curves shown, no significant differences in the cancer-specific survival were observed between surgery and ET group. The one, three, five-year disease-specific survival rate of patients who underwent surgical resection researched $89.3 \%, 81.7 \%$ and $77.1 \%$, respectively, which is similar to that after ET (89.9\%, $81.9 \%$ and $78.3 \%$, respectively). It suggested that ET was not inferior to surgery in short- and longterm survival outcomes. 
Furthermore, we conducted a Cox proportional hazards regression model to evaluate the impact of other variable on cancer-specific survival and demonstrated that additional variables, such as year at diagnosis, grade, tumour extension were also independent prognostic factors for disease-specific mortality after adjusting for other factors. In addition, we compared survival outcomes of surgery or ET according to different age, year, grade, tumour extension. For patients with T1a, well/moderately differentiated tumour, no significant survival benefit was observed. However, patients with T1b, poorly differentiated/undifferentiated tumour who received ET had worse survival outcomes in relation to patients who underwent surgery. Compared with duration about 1998-2001, there was no statistical significance between ET and surgery among patients who was diagnosed during 2006-2010.

\section{Discussion}

As the population ages, it is well anticipated that the number of elderly patients with early gastric cancer would continue to increase ${ }^{6,14}$. Although curative gastrectomy is a preferred treatment for early gastric cancer $(E G C)^{15}$, a less invasive alternative, endoscopic treatment, is very attractive in this respect. While gastrectomy could provide adequate curative resection of EGC, it also caused higher risk of perioperative morbidities and gastrointestinal dysfunction as well as decreased quality of life ${ }^{16-18}$. Therefore, the optimal treatment strategy for elderly population is a challenge for gastroenterologists and raises great concerns. For elderly patients with some comorbidities, the less invasive treatment, endoscopic treatment, might be a more suitable approach compared to surgery ${ }^{19}$. According to previous studies, ET, either ESD or EMR had been proved as a feasible and safe technique for the early gastric cancer with appropriate indications ${ }^{20-22}$. Besides, it was reported that the clinical and survival outcomes of ET were not inferior to those of surgery, especially for ESD ${ }^{23}$. Therefore, it is reasonable to presume that ET was a safety and promising tool for EGC that fulfilled certain indication criterion. At presently, however, limited studies directly compared survival outcomes of ET with those of surgery, especially for elderly patients. Chiu et al $^{16}$. reported that similar oncological outcomes between ESD and radical gastrectomy in 144 patients with EGC. Compared with surgery group, ESD group had better perioperative outcomes, less complication rate, and hospital stay ${ }^{16}$. In another study by Park et al $^{23}$. Outcomes of surgery and ESD were compared in 518 elderly patients with EGC and overall survival did not differ among two groups. In addition to limited patients' size, those population were all from Asia and the conclusion may not be applicable to Western patients. Therefore, large population-based studies from other regions need to be conducted.

In present study, we included 5639 patients to investigated the survival outcomes of different treatments in elderly patients with EGC. Among them, 2193 patients (52\%) received either gastrectomy or endoscopic treatments. Gastrectomy was still the mainstay of treatment for older patients with EGC. However, no disease-specific survival difference between ET and surgery groups was noticed in the current study. Furthermore, the similar disease-specific survival rate at one, three and five years after ET or surgery also indicated the effectiveness of ET. In Cox regression, tumour stage, grade, extension and year at diagnosis 
were also significantly associated with cancer-specific mortality. Given the lack of detailed data in the SEER database regarding ET, this study could not identify whether it was performed by ESD or EMR. The results of this study appear to be in accordance with former studies. According to previous studies, ET, especial for ESD, had high resection rates with minimal associated adverse events ${ }^{24}$. Compared with surgery, the advantage of ET is maintaining general function of stomach and good quality of life after treatment. Therefore, for elderly patients, the less invasive treatment might be a preferred choice in consideration of the aforementioned complications for surgery.

Despite of a larger population-based study, our study still had some limitations that warrant further discussions. Firstly, this study was the retrospective analysis from a single country and obvious selection bias was inevitable according to the treatment modality. Secondly, the database did not include comorbidities, disease progression or recurrence, and details on endoscopic resection procedures. Despite these limitations, our study also provided some evidence about feasibility and validity of ET for elderly patients with EGC.

In conclusion, ET is a promising and safe therapy for elderly patients with EGC. Because of similar survival outcomes between the patients who undergo ET and surgery, ET could be considered as an initial treatment option for elderly patients, which might have implications for therapy decision making. More well-designed large clinical studies are further needed to confirm the utility of ESD among elderly patients with EGC.

\section{Abbreviations}

ET, endoscopic treatment; EGC, early gastric cancer

\section{Declarations}

\section{Ethics approval and consent to participate}

Approval from the ethical board was not required.

\section{Consent for publication}

Not applicable

\section{Availability of data and materials}

The datasets analysed during the current study are publicly available

\section{Competing interests}

The author discloses no conflict 


\section{Funding Statement}

This work was supported by Zhejiang Provincial Medical and Healthy Science and Technology Projects [2018RC053].

\section{Authors' contributions}

HTC and XKH had the concept for the study; YFT, LL, HTC and XKH conducted data extraction and statistical analysis; XKH wrote the first draft of the manuscript; All authors edited and critically revised the final version of the manuscript.

\section{Acknowledgement}

We thank the National Cancer Institute's SEER Program for collection of the SEER data.

\section{References}

1. Ferlay J, Soerjomataram I, Dikshit R, Eser S, Mathers C, Rebelo M, et al. Cancer incidence and mortality worldwide: sources, methods and major patterns in GLOBOCAN 2012. Int J Cancer. 2015;136:E359-86.

2. Jemal A, Siegel R, Xu J, Ward E. Cancer statistics, 2010. CA Cancer J Clin. 2010;60:277-300.

3. Tsukuma H, Oshima A, Narahara H, Morii T. Natural history of early gastric cancer: a non-concurrent, long term, follow up study. Gut. 2000;47:618-21.

4. Hamashima C, Shibuya D, Yamazaki H, Inoue K, Fukao A, Saito H, et al. The Japanese guidelines for gastric cancer screening. Jpn J Clin Oncol. 2008;38:259-67.

5. Matsushita I, Hanai H, Kajimura M, Tamakoshi K, Nakajima T, Matsubayashi Y, et al. Should gastric cancer patients more than 80 years of age undergo surgery? Comparison with patients not treated surgically concerning prognosis and quality of life. J Clin Gastroenterol. 2002;35:29-34.

6. DePinho RA. The age of cancer. Nature. 2000;408:248-54.

7. Lee SR, Kim HO, Yoo CH. Impact of chronologic age in the elderly with gastric cancer. J Korean Surg Soc. 2012;82:211-8.

8. Murata A, Muramatsu K, Ichimiya Y, Kubo T, Fujino Y, Matsuda S. Endoscopic submucosal dissection for gastric cancer in elderly Japanese patients: an observational study of financial costs of treatment based on a national administrative database. J Dig Dis. 2014;15:62-70.

9. Eguchi T, Fujii M, Takayama T. Mortality for gastric cancer in elderly patients. J Surg Oncol. 2003;84:132-6.

10. Ono H, Kondo H, Gotoda T, Shirao K, Yamaguchi H, Saito D, et al. Endoscopic mucosal resection for treatment of early gastric cancer. Gut. 2001;48:225-9. 
11. Japanese Gastric Cancer A. Japanese gastric cancer treatment guidelines 2010 (ver. 3). Gastric Cancer. 2011;14:113-23.

12. Gotoda T. Endoscopic resection of early gastric cancer. Gastric Cancer. 2007;10:1-11.

13. Sarfati D, Koczwara B, Jackson C. The impact of comorbidity on cancer and its treatment. CA Cancer J Clin. 2016;66:337-50.

14. Monson K, Litvak DA, Bold RJ. Surgery in the aged population: surgical oncology. Arch Surg. 2003;138:1061-7.

15. Okamura T, Tsujitani S, Korenaga D, Haraguchi M, Baba H, Hiramoto Y, et al. Lymphadenectomy for cure in patients with early gastric cancer and lymph node metastasis. Am J Surg. 1988;155:476-80.

16. Chiu PW, Teoh AY, To KF, Wong SK, Liu SY, Lam CC, et al. Endoscopic submucosal dissection (ESD) compared with gastrectomy for treatment of early gastric neoplasia: a retrospective cohort study. Surg Endosc. 2012;26:3584-91.

17. Wu CW, Lo SS, Shen KH, Hsieh MC, Lui WY, P'Eng FK. Surgical mortality, survival, and quality of life after resection for gastric cancer in the elderly. World J Surg. 2000;24:465-72.

18. Katai H, Sasako M, Sano T, Maruyama K. The outcome of surgical treatment for gastric carcinoma in the elderly. Jpn J Clin Oncol. 1998;28:112-5.

19. Kusano C, Iwasaki M, Kaltenbach T, Conlin A, Oda I, Gotoda T. Should elderly patients undergo additional surgery after non-curative endoscopic resection for early gastric cancer? Long-term comparative outcomes. Am J Gastroenterol. 2011;106:1064-9.

20. Shimura T, Joh T, Sasaki M, Kataoka H, Tanida S, Ogasawara N, et al. Endoscopic submucosal dissection is useful and safe for intramucosal gastric neoplasms in the elderly. Acta Gastroenterol Belg. 2007;70:323-30.

21. Isomoto H, Ohnita K, Yamaguchi N, Fukuda E, Ikeda K, Nishiyama H, et al. Clinical outcomes of endoscopic submucosal dissection in elderly patients with early gastric cancer. Eur $\mathrm{J}$ Gastroenterol Hepatol. 2010;22:311-7.

22. Etoh T, Katai H, Fukagawa T, Sano T, Oda I, Gotoda T, et al. Treatment of early gastric cancer in the elderly patient: results of EMR and gastrectomy at a national referral center in Japan. Gastrointest Endosc. 2005;62:868-71.

23. Park CH, Lee H, Kim DW, Chung H, Park JC, Shin SK, et al. Clinical safety of endoscopic submucosal dissection compared with surgery in elderly patients with early gastric cancer: a propensity-matched analysis. Gastrointest Endosc. 2014;80:599-609.

24. Probst A, Pommer B, Golger D, Anthuber M, Arnholdt H, Messmann H. Endoscopic submucosal dissection in gastric neoplasia - experience from a European center. Endoscopy. 2010;42:1037-44.

\section{Figures}




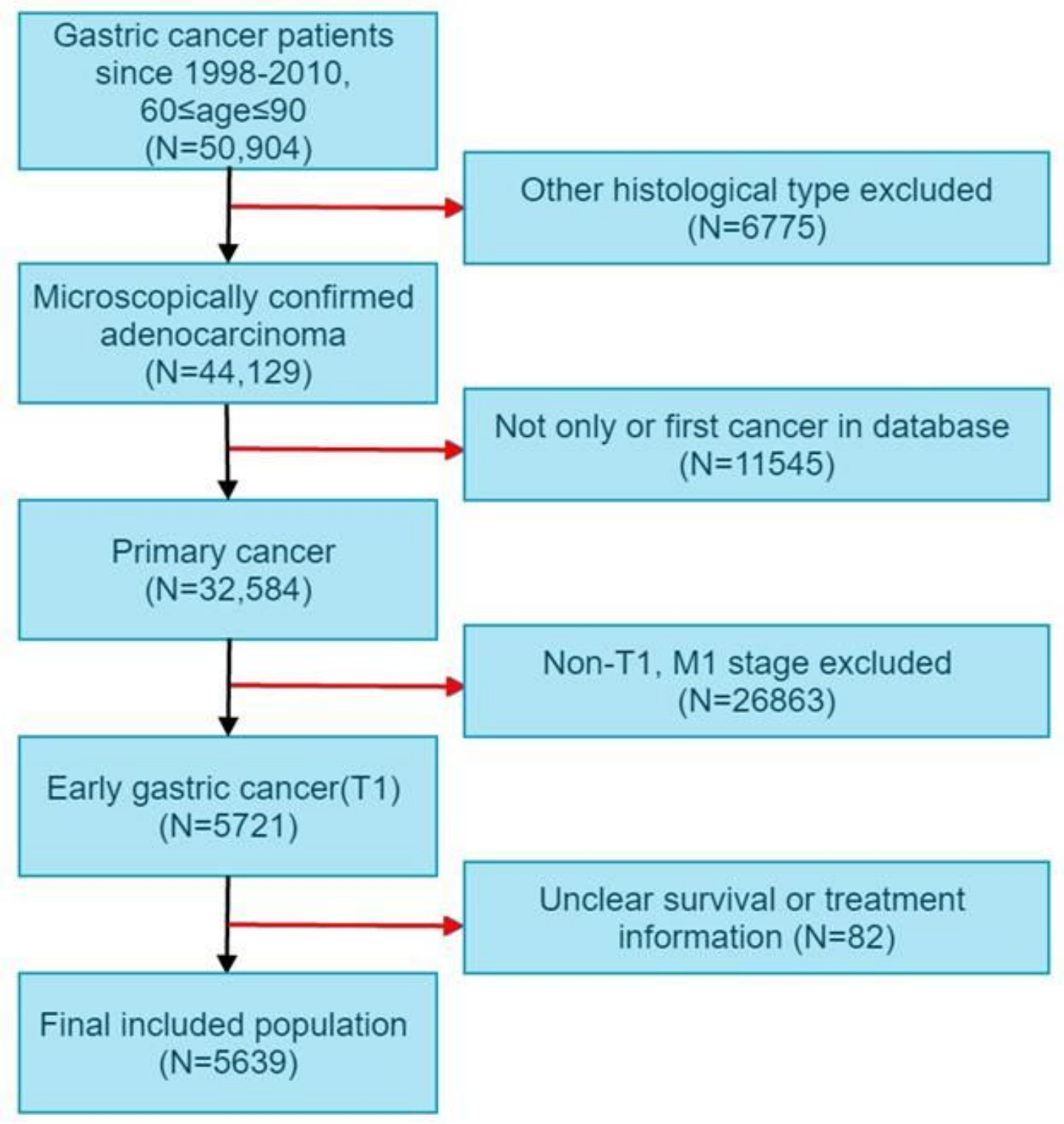

\section{Figure 1}

Detailed and stepwise selection flowchart 
Five-year cancer-specific survival

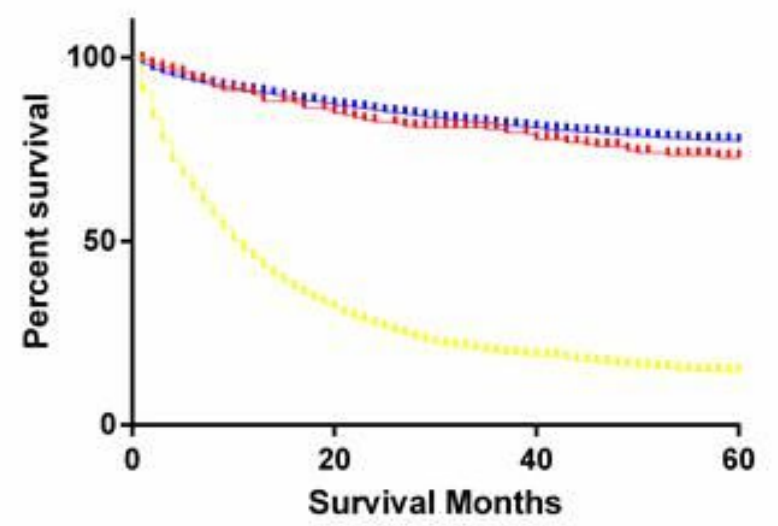

C No surgery/ET $+E T+$ Surgery

Three-year cancer-specific survival
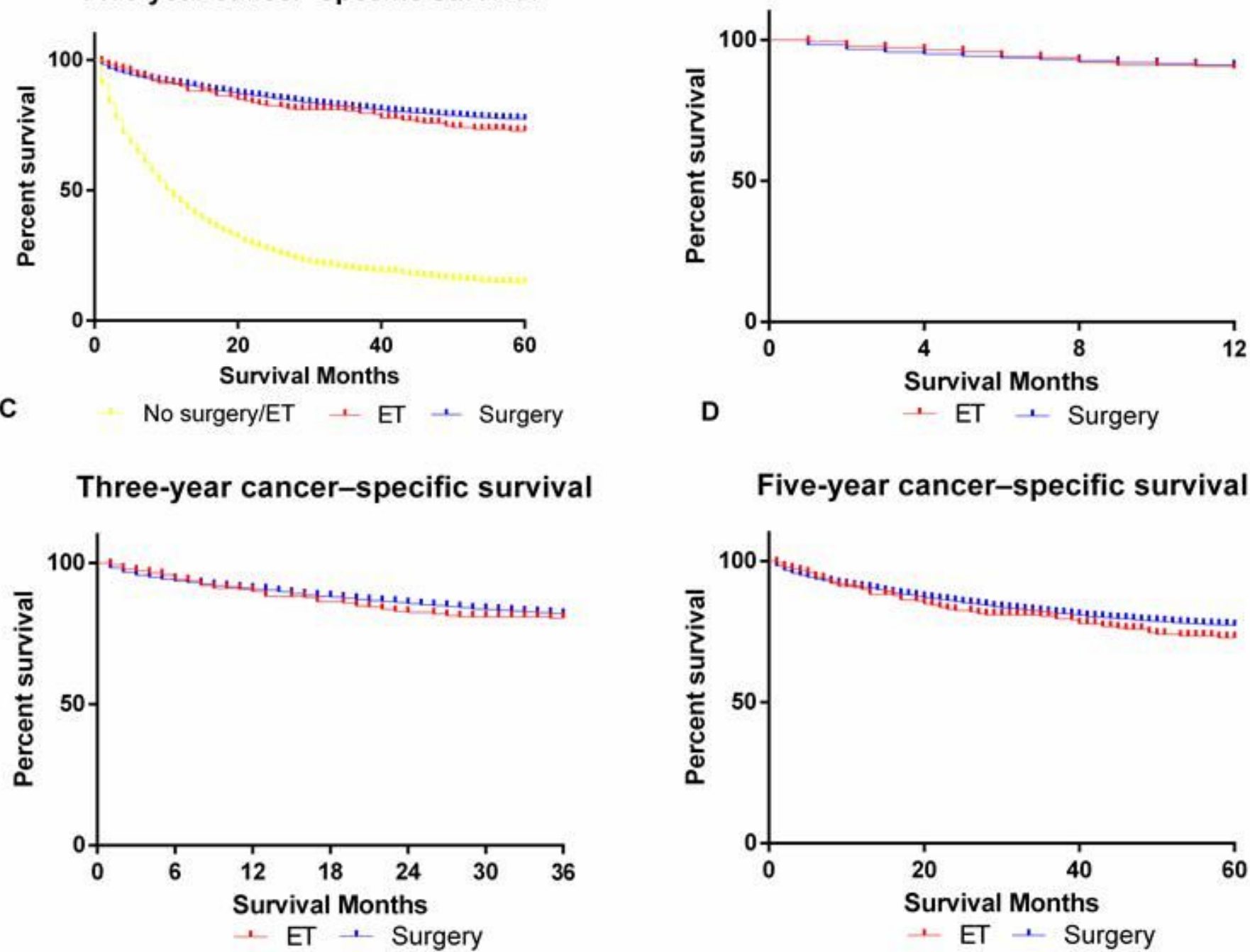

Five-year cancer-specific survival

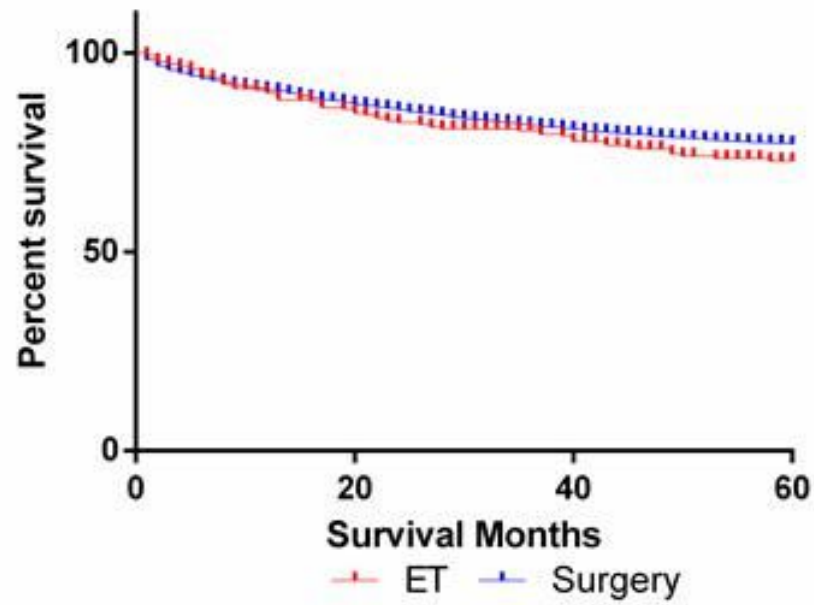

Figure 2

Kaplan-Meier cancer-specific survival curves for patients with early gastric cancer. A, five-year survival for overall population. B, C, D for people received either ET or surgery, B, one-year survival. C, three-year survival $D$, five-year survival. 